\title{
TUFM-knockdown inhibits the migration and proliferation of gastrointestinal stromal tumor cells
}

\author{
XIAOYUAN WENG ${ }^{1 *}$, SONG ZHENG ${ }^{2 *}$, HANLI SHUI $^{3}$, GUOSHENG LIN $^{3}$ and YONGJIAN ZHOU ${ }^{3}$ \\ ${ }^{1}$ Department of Surgery, Department of Clinical Medicine, Quanzhou Medical College, Quanzhou, Fujian 362010; \\ ${ }^{2}$ Department of Medical Oncology, Affiliated Hangzhou First People's Hospital, \\ Zhejiang Chinese Medical University Affiliated Hangzhou First Hospital, Hangzhou, Zhejiang 310006; \\ ${ }^{3}$ Department of Gastric Surgery, Union Hospital of Fujian Medical University, Fuzhou, Fujian 350001, P.R. China
}

Received January 13, 2020; Accepted August 4, 2020

DOI: $10.3892 / 01.2020 .12113$

\begin{abstract}
Gastrointestinal stromal tumors (GISTs) are the most common pathologic type of mesenchymal tumor in the digestive tract. Patients with GIST face the risk of metastasis, postoperative recurrence and imatinib mesylate (IM) resistance. Mitochondrial Tu translation elongation factor (TUFM) is highly expressed in GISTs, and is associated with oncogenesis, progression and prognosis. There is evidence that TUFM is involved in tumor invasion and metastasis. However, the effect of TUFM on GIST-T1 cells and the IM-resistant GIST-IR cell line remains unclear. The present study aimed to evaluate the effects of TUFM on the proliferation, migration and apoptosis of GIST cells in vitro. TUFM short hairpin (sh)RNA expression plasmids were transfected into GIST-T1 and GIST-IR cells by electroporation. The expression levels of enhanced green fluorescent protein were observed by fluorescence microscopy to evaluate the electroporation efficiency. The expression levels of TUFM were detected by western blot analysis and reverse transcription-quantitative PCR. Cell proliferation was assessed by counting cells and using a Cell Counting Kit- 8 assay. Cell migration was analyzed using wound healing and Transwell migration assays. Cell cycle distribution and late apoptosis were assessed by flow cytometry. TUFM shRNA expression plasmids were successfully transfected into the GIST cell line by electroporation. The transfection efficiency was $>75 \%$, and the TUFM gene silencing efficiency was $73.2 \pm 1.4 \%$. TUFM-knockdown decreased the proliferation and migration capacity of GIST-T1 and GIST-IR cells. The proportion of cells in the pre-G1 stage
\end{abstract}

Correspondence to: Dr Yongjian Zhou, Department of Gastric Surgery, Union Hospital of Fujian Medical University, 29 Xinquan Road, Fuzhou, Fujian 350001, P.R. China

E-mail: zhouyongjian9@126.com

*Contributed equally

Key words: gastrointestinal stromal tumors, mitochondrion, imatinib mesylate resistance, mitochondrial Tu translation elongation factor, GIST-T1 cell line was increased without change in the proportions of cells in the $\mathrm{G}_{1}, \mathrm{~S}$ and $\mathrm{G}_{2} / \mathrm{M}$ stages after TUFM silencing in GIST-T1 and GIST-IR cells. TUFM may be related to GIST infiltration and metastatic recurrence, suggesting that TUFM may be an effective target for preventing the progression and metastasis of GISTs.

\section{Introduction}

Gastrointestinal stromal tumors (GISTs) are the most common pathologic type of mesenchymal tumors in the digestive tract (1). Most patients face the challenges of early hematogenous metastasis, postoperative recurrence and poor clinical outcomes (2). Worldwide, a total of $20 \%$ of patients are primarily resistant to imatinib mesylate (IM), and $50 \%$ of patients exhibit drug resistance within 18-24 months, which leads to disease progression and even death (3). A total of $90 \%$ of GISTs have a gain-of-function mutation in KIT proto-oncogene, receptor tyrosine kinase (KIT) or platelet-derived growth factor receptor $\alpha$ (PDGFRA), which belong to the receptor tyrosine kinase family and can self-activate without any tyrosine kinase ligands $(4,5)$. Another $10 \%$ of GISTs lack the aforementioned mutation and are referred to as wild-type GISTs. Succinate dehydrogenase dysfunction occurs in mitochondria (6). Mitochondrial dysfunction is considered to be closely associated with tumor occurrence, development and drug resistance $(7,8)$. Therefore, the role of mitochondria in tumor formation has become the frontier of current research.

Mitochondrial Tu translation elongation factor (TUFM) is the most highly expressed protein in mitochondria (9). This protein initiates the polypeptide chain extension cycle and is involved in almost all mitochondrial protein translation (10). Several studies have demonstrated that TUFM is highly expressed in gastric cancer, esophageal cancer, GISTs and other gastrointestinal tumors (11-15). Related proteomics studies have observed that TUFM expression is associated with the risk classification and prognosis of GISTs (13). Therefore, it is reasonable to hypothesize that TUFM may be related to the occurrence, invasion and metastasis of GISTs. However, the role of TUFM in GISTs is still unclear.

IM is the most commonly used target drug for patients with GIST. IM extends the median survival of patients who are diagnosed at late stages and thus cannot undergo surgical resection (16). 
In the present study, the relationship among TUFM, GIST-T1 cells and IM-resistant cells was studied in vitro. By inhibiting TUFM expression in GIST-T1 cells and IM-resistant cells, novel outlooks for GIST treatment can be provided.

\section{Materials and methods}

Cell lines and culture. The GIST-T1 (passage 20) mutant-type cell line has a base deletion of $57 \mathrm{bp}$ in KIT exon 11 (PMC GIST01C; Cosmo Bio Co.,Ltd.) (17). GIST-IR cells (passage 23) were induced by treating GIST-T1 cells with $50 \mu \mathrm{g} / \mu 1 \mathrm{IM}$ (Glivec). GIST-IR drug-resistant cell lines were established by the gradient method, as previously described (18). No secondary mutations were observed in KIT/PDGFR exon sequencing analysis (19). GIST-T1 and GIST-IR cells were cultured in RPMI 1640 medium (Gibco; Thermo Fisher Scientific, Inc.) with $15 \%$ fetal bovine serum (TransGen Biotech Co., Ltd.) in an incubator at $37^{\circ} \mathrm{C}$ with $5 \% \mathrm{CO}_{2}$ without antibiotics.

TUFM silencing plasmids and electric transfection. pcDNA3.1-EGFP-TUFM-shRNA plasmids were constructed and designed with Primer Premier 5.0 (http://www.premierbiosoft.com/primerdesign) by using the TUFM fragment of the human gene acquired from NCBI GenBank (https://www. ncbi.nlm.nih.gov/)(source, Oryctolagus cuniculus). The primer sequences were as follows: Forward, 5'-GCAAGCTTGTGG ACATCTTCCAGGAGTA-3' and reverse, 5'-GCGAATTCC TTTGGTCTGCATTCACATT-3'.

Construction and identification of the pcDNA3.1EGFR-TUFM-shRNA were performed by Invitrogen; Thermo Fisher Scientific, Inc. The pcDNA3.1 vector, EcoRI and HindIII restriction enzymes, and T7-DNA ligase were purchased from Invitrogen; Thermo Fisher Scientific, Inc. The length of the target gene was $225 \mathrm{bp}$, and the results were confirmed by sequencing (20).

The experiment was divided into three groups: pcDNA3.1-EGFP-TUFM-shRNA plasmid $(1 \mu \mathrm{g} / \mu \mathrm{l})$ was transferred in the TUFM-shRNA group (TUFM shRNA), pcDNA3.1 vector was transfected in the negative control group (Control) and no transfection was conducted in the blank group (Blank). Electric transfection equipment (CTX-1500A; Celetrix Biotechnology Co., Ltd.) was used for electroporation according to the manufacturer's protocols. Briefly, $2 \times 10^{6}$ cells were harvested and resuspended in $120 \mu \mathrm{l}$ electrotransfer solution (Celetrix Biotechnology Co., Ltd.) and $2 \mu 1$ plasmid $(1 \mu \mathrm{g} / \mu \mathrm{l})$. The cell mixture was immediately added to the electric tube. The setting procedure of the system was as follows: 570 volts, $30 \mathrm{msec}, 1$ time. After electroporation, the cell mixture was divided into three parts that were resuspended in RPMI 1640 medium containing 15\% FBS and seeded in a 6-well plate for $24 \mathrm{~h}$ at $37^{\circ} \mathrm{C}$ before subsequent experiments.

Reverse transcription quantitative $(R T-q) P C R$. Total RNA was extracted by TRIzol reagent (Invitrogen; Thermo Fisher Scientific,Inc.) according to the manufacturers' protocol. TaqMan miRNA RT-kit (Invitrogen; Thermo Fisher Scientific, Inc.) was used to convert total miRNAs into corresponding cDNAs. The RT reaction conditions were as follows: $37^{\circ} \mathrm{C}$ for $15 \mathrm{~min}, 85^{\circ} \mathrm{C}$ for $5 \mathrm{sec}$ and $4^{\circ} \mathrm{C}$ for $5 \mathrm{~min}$. Subsequently, cDNA was used as template for PCR amplification by SYBR ${ }^{\mathrm{TM}}$ Green Master Mix
(Thermo Fisher Scientific, Inc.) according to the manufacturers' instructions. The sequences of the primers were as follows: TUFM, forward, 5'-ATCCGGGAGCTGCTCACCGA-3', reverse, 5'-ATGCTGTGGACACTTACATA-3'; and GAPDH, forward, 5'-AGGTCGGTGTGAACGGATTTG-3' and reverse 5'-GGGGTCGTTGATGGCAACA-3'. GAPDH was used as the reference gene. The thermocycling conditions for qPCR were as follows: $94^{\circ} \mathrm{C}$ for $2 \mathrm{~min}$ for $1 \mathrm{cycle}, 95^{\circ} \mathrm{C}$ for $40 \mathrm{sec}, 60^{\circ} \mathrm{C}$ for $35 \mathrm{sec}$ and $72^{\circ} \mathrm{C}$ for $1 \mathrm{~min}$ for 40 cycles. The expression level of TUFM was analyzed using the $2^{-\Delta \Delta \mathrm{Cq}}$ method (21).

Western blotting. Cells were harvested when confluence reached $90 \%$ and total protein was extracted using Total Protein Extraction Kit (cat. no. P0033; Beyotime Institute of Biotechnology) according to the manufacturers' protocol. Total protein concentration was determined by BCA method (22). Proteins $(20 \mu \mathrm{g})$ were separated by $10 \%$ SDS-PAGE (cat. no. P0052A; Beyotime Institute of Biotechnology) and transferred onto PVDF membranes (cat. no. FFP24; Beyotime Institute of Biotechnology). Membranes were blocked using Western blocking solution (cat. no. P0023B; Beyotime Institute of Biotechnology) at $25^{\circ} \mathrm{C}$ for $60 \mathrm{~min}$ and incubated with primary antibodies against TUFM (cat. no. ab155328; Abcam; 1:500) and GAPDH (cat. no. ab8254; Abcam; $1: 500$ ) at $25^{\circ} \mathrm{C}$ for $120 \mathrm{~min}$. Membranes were then incubated with Goat polyclonal secondary antibody to Mouse IgG-H\&L (Alexa Fluor ${ }^{\circledR} 488$; cat. no. ab150113; Abcam; 1:5,000) at $25^{\circ} \mathrm{C}$ for $60 \mathrm{~min}$. Proteins were detected using DAB Horseradish Peroxidase Color Development Kit (cat. no. P00203; Beyotime Institute of Biotechnology). The data were analyzed via densitometry using ImageJ $1.52 \mathrm{n}$ software (National Institutes of Health).

Cell morphology and fluorescence assessment. GIST-T1 and GIST-IR cells were plated in 6-well dishes at a density of $1 \times 10^{5}$ cells $/ \mathrm{ml}$. Cell morphology and fluorescence were observed under an inverted fluorescence microscope (magnifications, $\mathrm{x} 40$ and $\mathrm{x} 100$ ).

Cell proliferation and viability assays. Cell proliferation was determined by manual cell counting. Cells were seeded on 24-well plates at a density of $5 \times 10^{4}$ cells $/ \mathrm{ml}$. Live cells were counted every $24 \mathrm{~h}$, and the average of three wells for 5 days was used to draw cell growth and inhibition curves. GIST-TI and GIST-IR cells were plated into 96-well plates at a density of $5 \times 10^{3}$ cells/well in triplicate. Subsequently, the cells were transfected with TUFM-shRNA plasmid and pcDNA3.1 vector. Cell viability was evaluated using CCK- 8 assays (Dojindo Molecular Technologies, Inc.) according to the manufacturer's protocol. The absorbance was determined at $450 \mathrm{~nm}$.

Wound healing and Transwell assays. GIST-T1 and GIST-IR cells were plated in 6-well plates at a density of $1 \times 10^{4}$ cells $/ \mathrm{ml}$ and cultured in RPMI-1640 medium with $15 \%$ fetal bovine serum at $37^{\circ} \mathrm{C}$ with $5 \% \mathrm{CO}_{2}$. After $24 \mathrm{~h}$, when the cells reached confluence in $90 \%$, a scratch was made in the middle of the plate, and the scratched cells were washed twice with PBS. The cells were cultured in RPMI-1640 medium with $2.5 \%$ fetal bovine serum at $37^{\circ} \mathrm{C}$ with $5 \% \mathrm{CO}_{2}$. Images of the samples were captured at 0,24 and $48 \mathrm{~h}$, and cell morphology was observed under an inverted fluorescence microscope (magnification, $\mathrm{x} 40$ ). ImageJ 


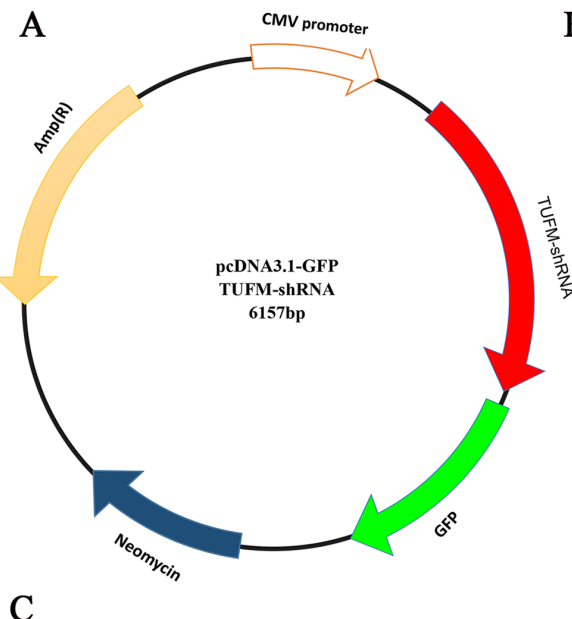

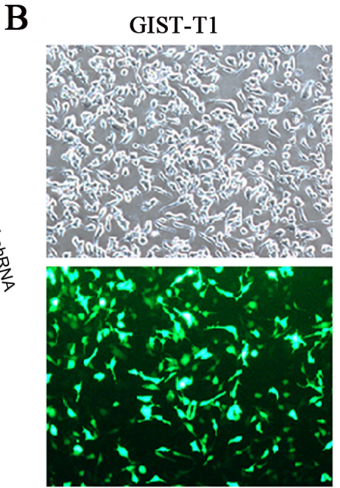

pcDNA3.1-EGFP-TUFM

$\mathrm{D}$

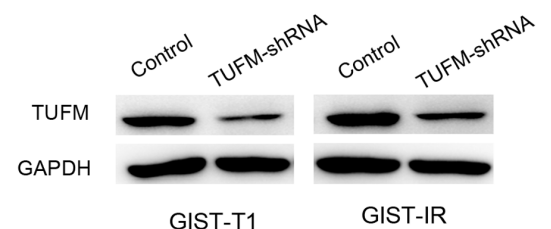

GIST-T1
GIST-IR

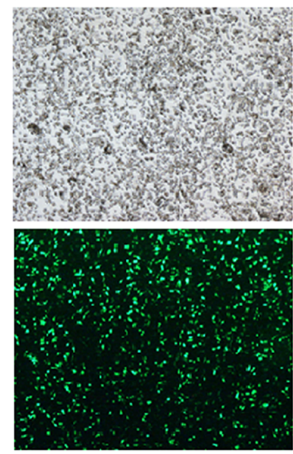

pcDNA3.1-EGFP-TUFM

GIST-IR
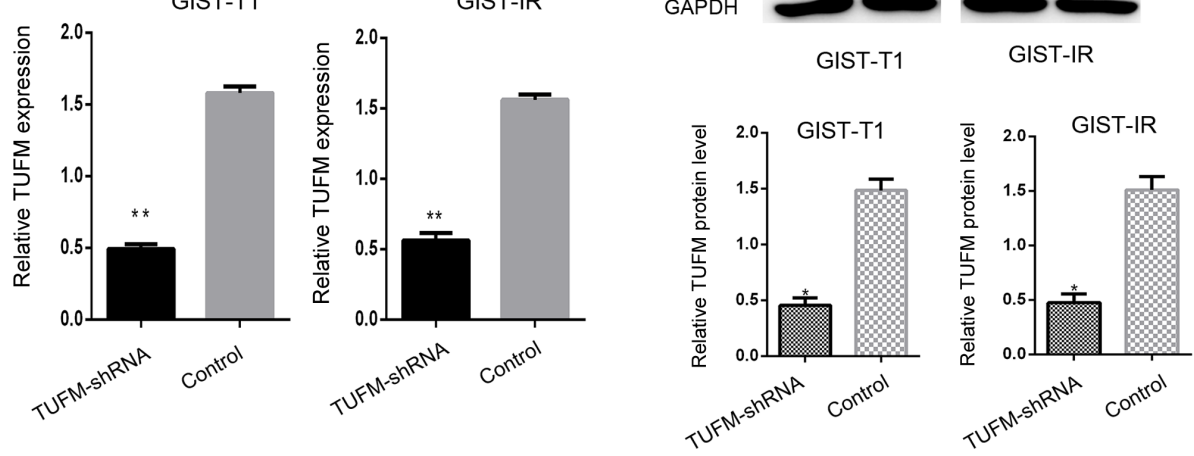

Figure 1. Construction of plasmids and evaluation of the knockdown efficiency of TUFM shRNA. (A) pcDNA3.1-EGFP plasmid was used as the vector to construct the pcDNA3.1-TUFM-shRNA plasmid. (B) Following transfection with pcDNA3.1-TUFM-shRNA plasmid, EGFP expression was observed in GIST-T1 (magnification, x100) and GIST-IR cells (magnification, $\mathrm{x} 40$ ) by inverted fluorescence microscopy. The results demonstrated that $75.2 \%$ of cells expressed the EGFP protein in both cell lines. (C) The results of reverse transcription-quantitative PCR demonstrated that the expression levels of TUFM mRNA in the TUFM shRNA group were lower than those in the control group. (D) Western blot analysis revealed that the protein expression levels of TUFM in GIST-T1 cells transfected with TUFM shRNA plasmid were significantly lower compared with those in the control group. The TUFM level was normalized to the protein level of GAPDH. ${ }^{*} \mathrm{P}<0.05$ and ${ }^{* *} \mathrm{P}<0.01$. TUFM, mitochondrial Tu translation elongation factor; shRNA, short hairpin RNA; GIST, gastrointestinal stromal tumor; EGFP, enhanced green fluorescent protein; ctrl, control.

$1.52 \mathrm{n}$ software was used to analyze and quantify the range of cell-free regions in the images.

For Transwell assays, TUFM shRNA and control groups of both GIST-T1 and GIST-IR cells were inoculated at a density of $5 \times 10^{4}$ cells $/ \mathrm{ml}$ in $8 \mu \mathrm{m}$-pore Transwell chambers (Corning). RPMI 1640 medium containing $2.5 \%$ FBS was added to the upper chamber whereas medium containing $15 \%$ FBS was added to the lower chamber. The cells were incubated for $24 \mathrm{~h}$ at $37^{\circ} \mathrm{C}$ with $5 \% \mathrm{CO}_{2}$, and cells in the upper chamber were stained with eosin at $25^{\circ} \mathrm{C}$ for $3 \mathrm{~min}$. The cells in five random fields were counted under an inverted fluorescence microscope (magnification, x100).

Cell cycle determination. TUFM shRNA and control groups of GIST-T1 and GIST-IR cells in the logarithmic phase were subjected to trypsin digestion and centrifugal $\left(4^{\circ} \mathrm{C}, 250 \mathrm{x} \mathrm{g}\right.$, $1 \mathrm{~min}$ ) precipitation. Subsequently, $1 \times 10^{6}$ cells $/ \mathrm{ml}$ cells were fixed with $75 \%$ ice-cold ethanol overnight at $4^{\circ} \mathrm{C}$. The cells were centrifuged at $1,000 \mathrm{x} \mathrm{g}$ for $3 \mathrm{~min}$ and the supernatant was discarded. The cells were resuspended in propidium iodide (PI; $10 \mu \mathrm{g} / \mathrm{ml})$ and RNase (5 $\mu \mathrm{g} / \mathrm{ml}$; PI Staining kit, Sangon Biotech Co., Ltd.), washed twice with PBS and incubated at $4^{\circ} \mathrm{C}$ for $30 \mathrm{~min}$. Subsequently, the supernatants were discarded after centrifugation $\left(4^{\circ} \mathrm{C}, 1,000 \times \mathrm{g}, 3 \mathrm{~min}\right)$, and the cells were washed once with PBS and transferred into a flow cytometer centrifuge tube to be measured on the machine. Flow cytometric analysis of $2 \times 10^{4}$ cells from each sample was performed on FACSort flow cytometer (BD Biosciences, Inc). FlowJo VX (BD Biosciences, Inc.) was used for analysis and late apoptosis assessment.

Statistical analysis. The results are represented as the mean \pm standard deviation of three independent repeats. Unpaired Student's t-test was performed to compare differences between two groups and one-way ANOVA followed by Ruhey's post hoc test was performed to compare differences among multiple groups. Data were analyzed using SPSS 20.0 software (IBM Corp.) or GraphPad Prism 6 (GraphPad Software, Inc.). $\mathrm{P}<0.05$ was considered to indicate a statistically significant difference.

\section{Results}

TUFM expression is markedly decreased after transfection of GIST-T1 cells with TUFM shRNA plasmid. The TUFM shRNA plasmid was constructed to knockdown TUFM protein expression in cells (Fig. 1A). After the TUFM shRNA plasmid was 

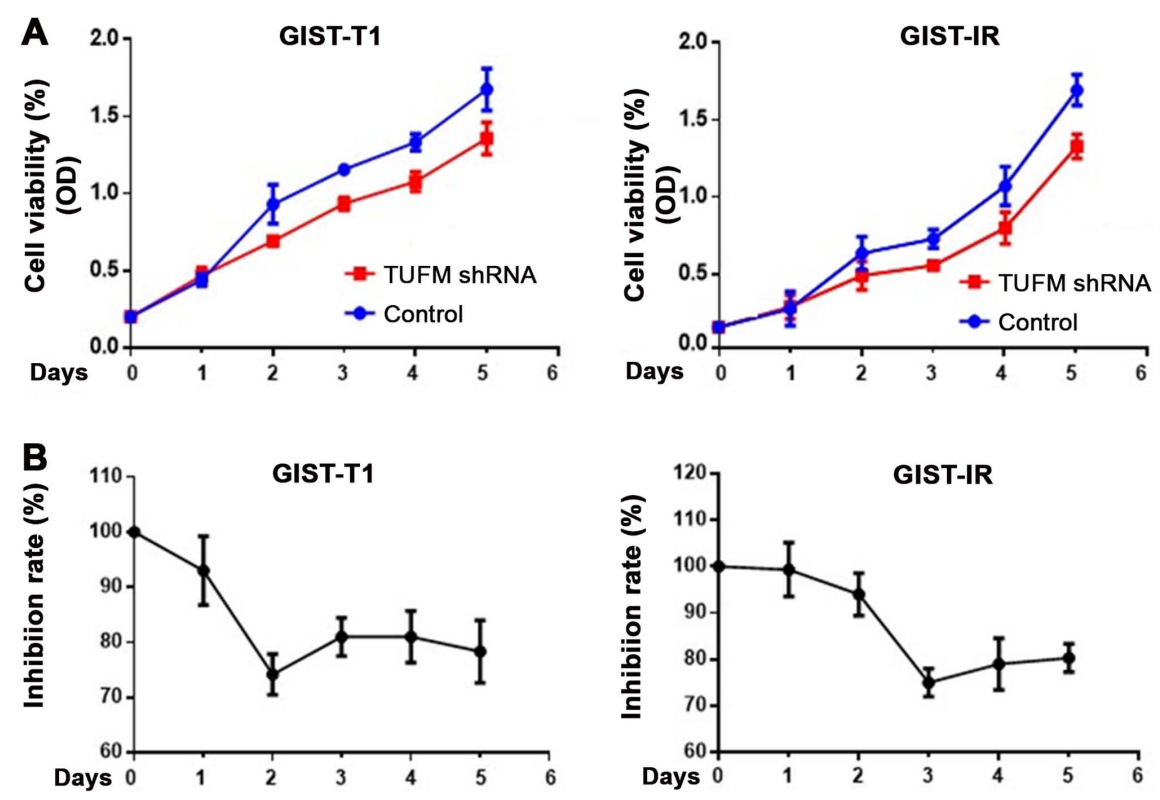

Figure 2. Silencing the TUFM gene decreases the cell viability and proliferation of GIST-T1 and GIST-IR cells. (A) CCK-8 assays demonstrated that TUFM silencing decreased cell viability in GIST-T1 and GIST-IR cells. (B) Inhibition rate results demonstrated that GIST-T1 and GIST-IR cells presented with the maximum inhibition effect on days 2 and 3 post TUFM shRNA transfection, respectively. TUFM, mitochondrial Tu translation elongation factor; sh, short hairpin; GIST, gastrointestinal stromal tumor; OD, optical density.
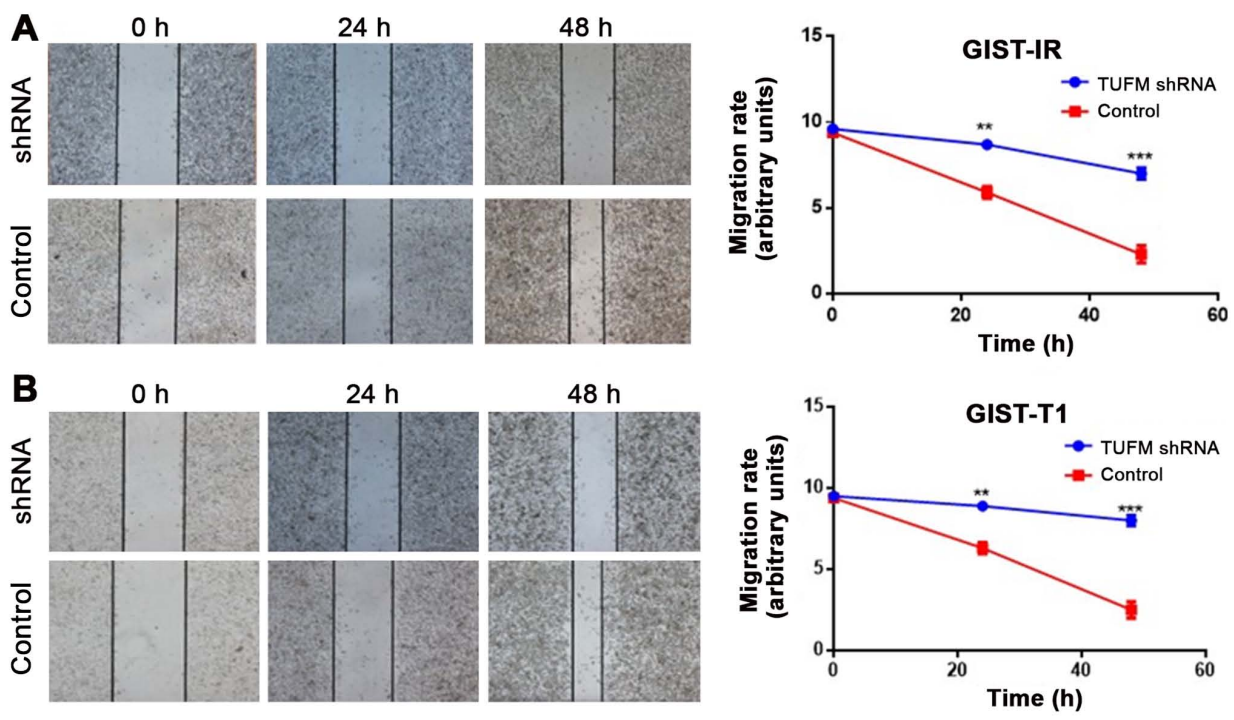

Figure 3.TUFM silencing suppresses the lateral migration of GIST-T1 and GIST-IR cells. Wound healing assays demonstrated that TUFM silencing inhibited the lateral movement of (A) GIST-T1 and (B) GIST-IR cells (magnification, $\mathrm{x} 40$ ). ${ }^{* *} \mathrm{P}<0.01$ and ${ }^{* * * *} \mathrm{P}<0.001$. TUFM, mitochondrial Tu translation elongation factor; sh, short hairpin; GIST, gastrointestinal stromal tumor; ctrl, control.

transfected into GIST-T1 and GIST-IR cells, EGFP-expressing cells were observed and counted by fluorescence microscopy. The transfection efficiency was $\sim 75 \%$ and no significant cell death was observed (Fig. 1B). Reverse transcription-quantitative (RT-q)PCR and western blot analyses demonstrated that the expression levels of TUFM were significantly reduced in the TUFM shRNA group compared with those in the control group (Fig. 1C and D).

TUFM-knockdown inhibits the viability and proliferation of GIST-T1 and GIST-IR cells. After TUFM was knocked down, cell viability was decreased in GIST-T1 and GIST-IR cells (Fig. 2A). Cells were counted for 5 consecutive days to determine cell viability. In addition, CCK-8 assays were used to detect the proliferation rate of GIST-T1 and GIST-IR cells. The results demonstrated that TUFM silencing inhibited proliferation of GIST-T1 cells, reaching its maximal effect at $48 \mathrm{~h}$ after transfection, and GIST-IR cells, reaching its maximal effect at $72 \mathrm{~h}$ after transfection (Fig. 2).

TUFM silencing suppresses the migration of GIST-T1 and GIST-IR cells. Wound healing assays demonstrated that, compared with the control groups, TUFM silencing significantly decreased the migratory rate of GIST-T1 and GIST-IR cells at $48 \mathrm{~h}$ after transfection (Fig. 3A and B). Additionally, 
A
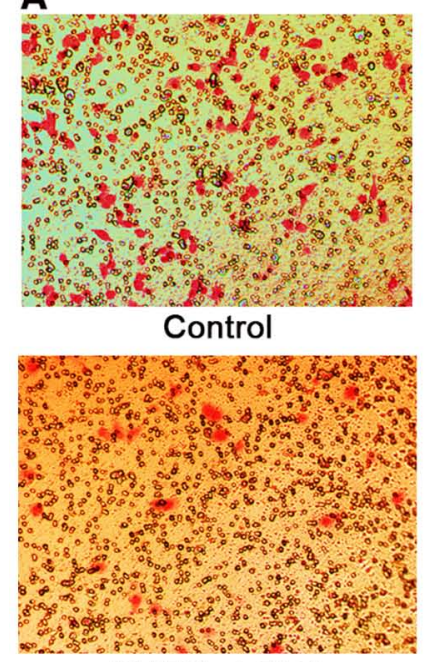

TUFM ShRNA

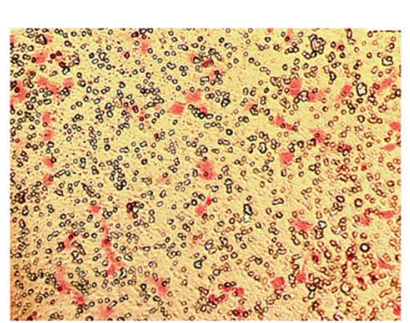

Blank

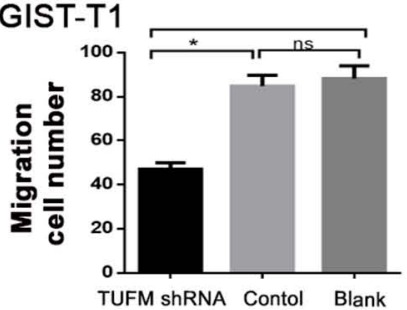

B
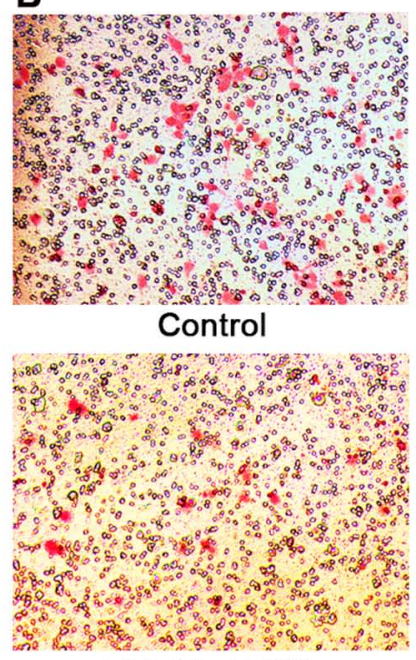

TUFM ShRNA

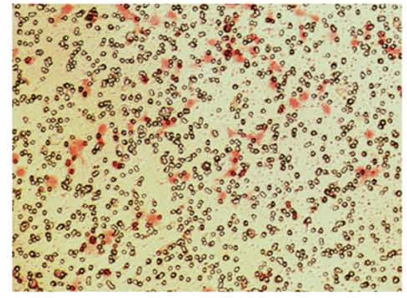

Blank

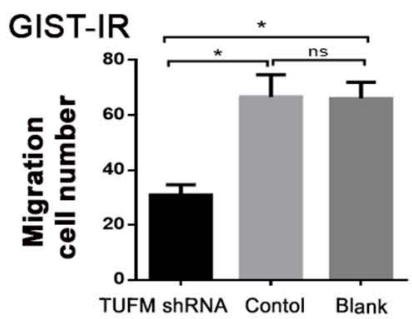

Figure 4. TUFM silencing suppresses the vertical migration of GIST-T1 and GIST-IR cells. GIST-T1 and GIST-IR cells transfected with TUFM shRNA plasmid were used for Transwell migration assays. Number of vertically migrating (A) GIST-T1 and (B) GIST-IR cells in the TUFM shRNA group was significantly lower compared with that in the control and blank groups (magnification, $\mathrm{x} 100$ ). ${ }^{*} \mathrm{P}<0.05$. TUFM, mitochondrial Tu translation elongation factor; sh, short hairpin; GIST, gastrointestinal stromal tumor; ns, not significant.

A
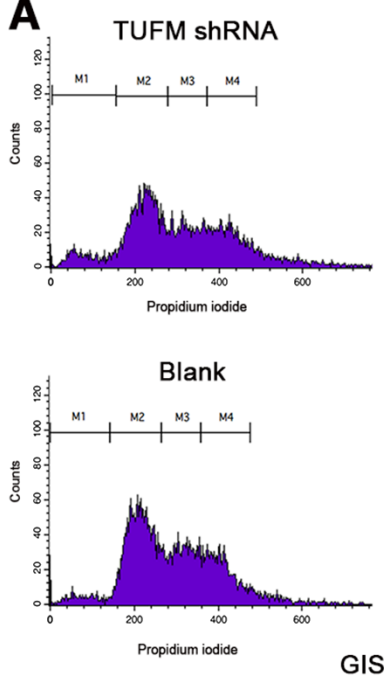
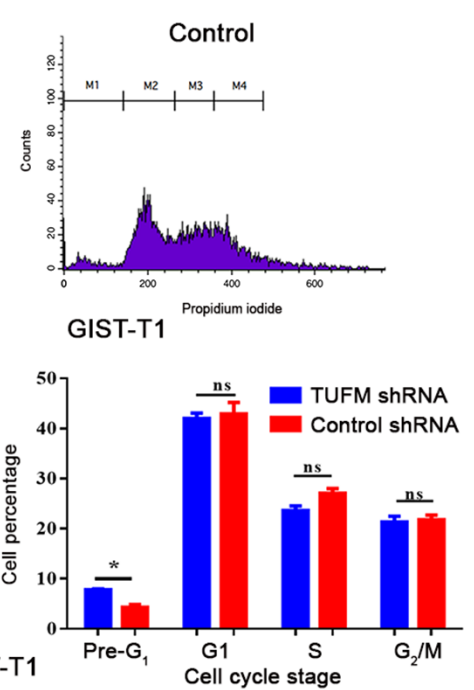
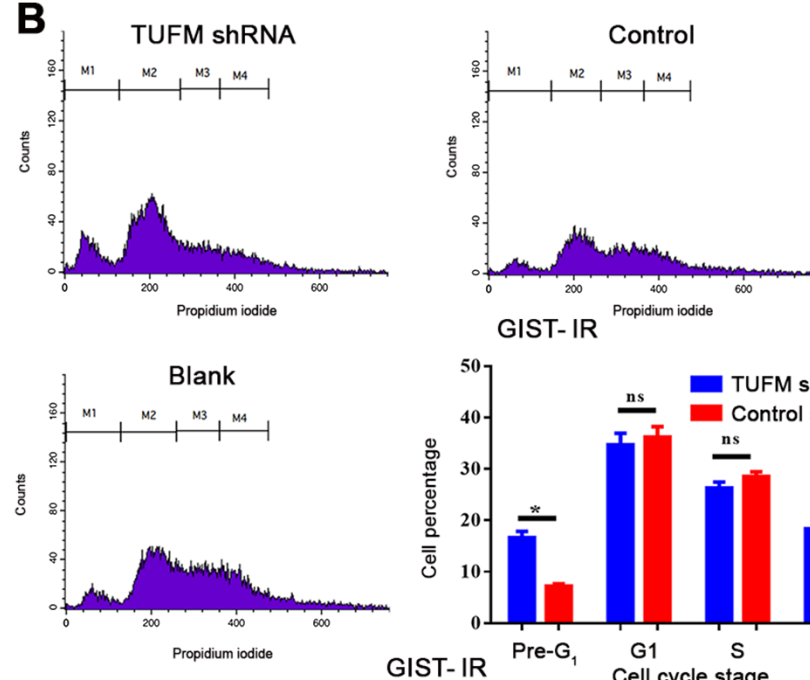

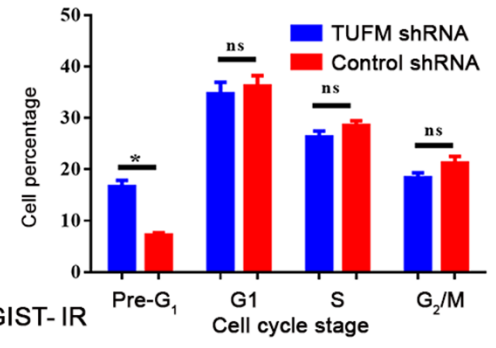

Figure 5. TUFM silencing increases late apoptosis in GIST-T1 and GIST-IR cells. Flow cytometry was used to detect the cell cycle of the TUFM shRNA, control and blank groups. The number of pre-G1 cells in the TUFM shRNA group was higher compared with that in the control group in (A) GIST-T1 and (B) GIST-IR cells. * $\mathrm{P}<0.05$. TUFM, mitochondrial Tu translation elongation factor; sh, short hairpin; GIST, gastrointestinal stromal tumor; ns, not significant.

Transwell migration assays demonstrated that, compared with those in the control and blank groups, the number of GIST-T1 and GIST-IR cells on the underside of the chamber membrane was significantly decreased after TUFM silencing $(\mathrm{P}<0.05$; Fig. 4). In addition no significant differences were observed between the control and blank groups in GIST-T1 and GIST-IR cells ( $\mathrm{P}>0.05$; Fig. 4).

TUFM affects late apoptosis and the cell cycle of GIST-T1 and GIST-IR cells. Cell cycle and late apoptosis were detected by flow cytometry. The results demonstrated that the proportion of GIST-T1 and GIST-IR cells in the pre- $\mathrm{G}_{1}$ phase was significantly higher in the TUFM shRNA group compared with in the GIST-T1 and GIST-IR cells in the control group
(Fig. 5). By contrast, no significant differences were observed in the proportions of GIST-T1 and GIST-IR cells in the $\mathrm{G}_{1}, \mathrm{~S}$ and $\mathrm{G}_{2} / \mathrm{M}$ phases between the two groups (Fig. 5).

\section{Discussion}

In 20 years of research, the study of GISTs has gradually advanced. A variety of molecular pathological mechanisms are involved in the occurrence, development and drug resistance of GISTs (23). Currently, GIST has one of the highest mortality rates among tumors worldwide (22). Genomic and proteomic studies of GIST tissue have revealed a variety of tumor-related molecules involved in the occurrence, development and drug resistance of GISTs (24). The high expression levels of TUFM 
in tumor tissues suggest that it may serve an important role in the process of tumorigenesis and development, and its association with KIT/PDGFRA remains unclear (25). The present study used an electroporation method to transfect a TUFM-silencing plasmid, which is considered to be the most efficient and convenient method of cell transfection in vitro (26). Combined with RNA interference technology, the function of TUFM in tumor cells can be evaluated quickly and can provide an effective platform for further study of related signaling pathways.

The results of cell counting and CCK-8 assays demonstrated that cell proliferation was significantly inhibited after silencing of the TUFM gene in GIST-T1 and GIST-IR cells. This is consistent with the results of Jhas et al (27), which demonstrated that cell proliferation was significantly inhibited by silencing of the TUFM gene in TEX leukemia cells. This effect is considered to be caused by changes in cell function related to reductions in oxygen consumption and mitochondrial membrane potential (28). A study by Sajid et al (29) demonstrated that inhibiting TUFM phosphorylation through drug treatment inhibited the protein synthesis and growth of cells. In addition, Ravn et al (30) observed that TUFM and other translation protein deficiencies in patients with clinical mitochondrial protein translation system defects cause lethal effects during the early neonatal period, whereas, in other patients, TUFM causes serious defects and oxidation-respiration chain enzyme dysfunction in the liver and muscle system. The importance of mitochondrial function in maintaining cell activity is clear. When TUFM is silenced, the synthesis of mitochondrial oxidative respiratory chain complex proteins becomes inhibited or dysfunctional, leading to decreased mitochondrial membrane potential and disrupted ATP synthesis. Subsequently, the disruption of energy supply leads to a lack of energy in the cells, and cell proliferation is inhibited (31). This may be the main reason why the in vitro silencing of TUFM inhibits cell proliferation. Therefore, the hypothesis that the decrease in mitochondrial function after the silencing of TUFM results in a decrease in cell viability and cell proliferation is valid.

In proteomic analysis of GISTs, the expression levels of TUFM in the high-risk group are higher than those in the low-risk group (13). Furthermore, GISTs in the high-risk group tend to have more aggressive tumor cells and worse prognosis (32). The results of the cell migration experiments performed in the present study demonstrated that the lateral and vertical migration of cells was decreased significantly following TUFM-knockdown. Therefore, it was proposed that interference with TUFM expression may inhibit the synthesis of adhesion proteins and lead to a decline in cell migration ability. In a study by Hashim et al (33), Mediterranean patients with colon cancer were less affected by invasion and metastasis. Notably, epidemiological analysis observed that the Mediterranean population consumed more olive oil than individuals in other areas. Through high-throughput microarray data analysis, it was demonstrated that olive oil may inhibit the function of TUFM and other related genes to inhibit colon invasion. Other studies have reported that olive oil may inhibit TUFM function by inhibiting integrin- $\alpha 2$ and integrin- $\alpha 6$ expression in tumor cells (34). As a cell surface receptor, integrin acts as a bridge for cell-cell interactions, and cell and extracellular matrix interactions. TUFM expression is positively associated with E-cadherin in lung cancer tissue and serves an important role in the epithelium during interstitial invasion and metastasis of lung cancer, possibly by recruiting $\beta$-cadherin to regulate lung cancer cell invasion and metastasis through protein kinase AMP-activated catalytic subunit $\alpha$ 2-GSK3 $\beta$ signaling (35). Additionally, abnormal mitochondrial energy metabolism, mitochondrial dysfunction, and inadequate ATP energy supply may be reasons for the cell migration inhibition caused by TUFM silencing.

The results of the cell cycle experiments performed in the present study demonstrated that following TUFM silencing in GIST-T1 and GIST-IR cells, there were no significant differences in the cell cycle distribution among the silenced, negative control and blank groups; however, the number of cells in the early $G_{1}$ phase was significantly increased. This early $G_{1}$ phase cell population is often considered to be associated with reduced PI staining, intracellular DNA degradation and characteristics of late apoptotic cells (36). These results suggested that TUFM silencing may promote late apoptosis. Lei et al (37) studied the synergistic effects of TUFM and NLRX1 (NLR family member $\mathrm{X} 1$ ), and reported that TUFM recruits autophagosomes, such as ATG5-ATG12, in mitochondria and promotes the activation of autophagy signaling pathways, leading to autophagy in mitochondria, and thus altering the dynamic intracellular mitochondria balance. Furthermore, Rakovic et al (38) observed that in a Parkinsonian pathological model, TUFM may be involved in the PTEN induced kinase 1/Parkin signaling pathway to promote autophagy in functionally defective mitochondria. It is now hypothesized that TUFM is involved in initiating mitochondrial autophagy and scavenging damaged mitochondria, thereby inhibiting tumor cell apoptosis induced by mitochondrial damage signaling pathways (39). Therefore, the results of the present study, which demonstrated that late apoptotic cells were increased in the TUFM-silenced GIST-T1 cell line, are consistent with the aforementioned research revealing inhibited mitochondrial autophagy and damaged mitochondrial scavenging in TUFM stable knockout mice and TUFM-silenced $293 \mathrm{~T}$ cells. These changes lead to considerable mitochondrial disintegration factor release and increased apoptosis (40). TUFM silencing directly induces mitochondrial protein synthesis inhibition, membrane dysfunction and mitochondrial structural dysfunction, which eventually leads to mitochondrial damage or disintegration, which is an important contributor to tumor cell apoptosis (41).

There are a number of challenges in the treatment of GISTs. TUFM may be involved in numerous tumor cell processes. The relationship between TUFM expression and the prognosis of patients with GIST, the relationship between TUFM and cell adhesion molecules, and the signaling pathway of TUFM require further study. In addition, as the present study was an in vitro study, further in vivo evaluation of TUFM function is required.

The present study investigated the effects of TUFM on the growth, migration and cell cycle of GIST cells in vitro. TUFM inhibited the growth and migration of GIST cell lines and promoted the apoptosis of tumor cells. These results suggested that TUFM may serve a role in reducing postoperative recurrence and metastasis in patients with GIST. Therefore, TUFM may become an effective target for inhibiting early hematogenous metastasis, postoperative recurrence and metastasis in patients with GIST, even in IM-resistant patients. 


\section{Acknowledgements}

Not applicable.

\section{Funding}

The present study was supported by the Chinese National Key Clinical College (grant no. 2492012), Fujian Provincial Health and Family Planning Key Personnel Training Program (grant no. 1033291) and Quanzhou City Science \& Technology Program of China (grant no. 2019N071S).

\section{Availability of data and materials}

The datasets used or analyzed during the current study are available from the corresponding author on reasonable request.

\section{Authors' contributions}

YZ, XW and SZ made substantial contributions to the conception and design of the study. XW, HS and GS performed the experiments. XW, HS and GL contributed significantly to data analysis. XW, YZ and SZ helped performing the analysis with constructive discussions. XW drafted the manuscript. YZ, $\mathrm{XW}$ gave final approval of the version to be published. YZ and XW agreed to be accountable for all aspects of the work in ensuring that questions related to the accuracy and integrity of any part of the work were appropriately investigated and resolved. All authors read and approved the final manuscript.

\section{Ethics approval and consent to participate}

Not applicable.

\section{Patient consent for publication}

Not applicable.

\section{Competing interests}

The authors declare that they have no competing interests.

\section{References}

1. Mazur MT and Clark HB: Gastric stromal tumors. Reappraisal of histogenesis. Am J Surg Pathol 7: 507-519, 1983.

2. Roggin KK and Posner MC: Modern treatment of gastric gastrointestinal stromal tumors. World J Gastroenterol 18: 6720-6728, 2012.

3. Søreide K, Sandvik OM, Søreide JA, Giljaca V, Jureckova A and Bulusu VS: Global epidemiology of gastrointestinal stromal tumors (GIST): A systematic review of population-based cohort studies. Cancer Epidemiol 40: 39-46, 2016.

4. Hirota S, Isozaki K, Moriyama Y, Hashimoto K, Nishida T, Ishiguro S, Kawano K, Hanada M, Kurata A, Takeda M, et al: Gain-of-function mutations of KIT in human gastrointestinal stromal tumors. Science 279: 577-580, 1998.

5. Hayashi Y, Bardsley MR, Toyomasu Y, Taguchi T, Rubin BP, Carter M, Ramachandran A and Ordog T: Abstract 1035: Crenolanib, a highly selective platelet-derived growth factor receptor/(PDGFRA/B) tyrosine kinase inhibitor, destabilizes ETV1 protein in KIT-mutant gastrointestinal stromal tumor (GIST) cells. Cancer Res 73 (Suppl 8): S1035, 2013.

6. Gill AJ: Succinate dehydrogenase (SDH) and mitochondrial driven neoplasia. Pathology 44: 285-292, 2012.
7. Yang WL, Addona T, Nair DG, Qi L and Ravikumar TS: Apoptosis induced by cryo-injury in human colorectal cancer cells is associated with mitochondrial dysfunction. Int J Cancer 103: 360-369, 2003

8. Ma L, Wang R, Duan H, Nan Y, Wang Q and Jin F: Mitochondrial dysfunction rather than mtDNA sequence mutation is responsible for the multi-drug resistance of small cell lung cancer. Oncol Rep 34: 3238-3246, 2015.

9. Shah ZH, Migliosi V, Miller SCM, Wang A, Friedman TB and Jacobs HT: Chromosomal locations of three human nuclear genes (RPSM12, TUFM, and AFG3L1) specifying putative components of the mitochondrial gene expression apparatus. Genomics 48: 384-388, 1998.

10. Wang S, Wei AC, Fu Z, Ruker J, Foster BD, O'Rourke B and Van Eyk JE: Abstract 16664: Cyclophilin D binds to tufm and suppresses mitochondrial translation. Circulation 130: A16664, 2014.

11. Zhang J, Huang JY, Chen YN, Yuan F, Zhang H, Yan FH, Wang MJ, Wang G, Su M, Lu G, et al: Erratum: Whole genome and transcriptome sequencing of matched primary and peritoneal metastatic gastric carcinoma. Sci Rep 5: 13750, 2015.

12. Hou J, Liao LD, Xie YM, Zeng FM, Ji X, Chen B, Li LY, Zhu MX, Yang CX, Zhao Q, et al: DACT2 is a candidate tumor suppressor and prognostic marker in esophageal squamous cell carcinoma. Cancer Prev Res (Phila) 6: 791-800, 2013.

13. Chen DB, JiangWZ, Hong CY, Wang QL, Hong ZP, Shi LP and Lin CP: Comparative proteomics study of KIT positive gastrointestinal stromal tumors based on risk stratification differences. Chinese J Exper Surg 34: 217-220, 2017.

14. Shi H, Hayes M, Kirana C, Miller R, Keating J, Macartney-Coxson D and Stubbs R: TUFM is a potential new prognostic indicator for colorectal carcinoma. Pathology 44: 506-512, 2012

15. Staab CA, Ceder R, Jägerbrink T, Nilsson JA, Roberg K, Jörnvall H, Höög JO and Grafström RC: Bioinformatics processing of protein and transcript profiles of normal and transformed cell lines indicates functional impairment of transcriptional regulators in buccal carcinoma. J Proteome Res 6: 3705-3717, 2007.

16. Bümming P, Andersson J, Meis-Kindblom JM, Klingenstierna $\mathrm{H}$, Engström K, Stierner U, Wängberg B, Jansson S, Ahlman H, Kindblom LG and Nilsson B: Neoadjuvant, adjuvant and palliative treatment of gastrointestinal stromal tumors (GIST) with imatinib: A center-based study of 17 patients. Br J Cancer 89: 460-464, 2003

17. Taguchi T, Sonobe H, Toyonaga SI, Yamasaki I, Shuin T, Takano A, Araki K, Akimaru K and Yuri K: Conventional and molecular cytogenetic characterization of a new human cell line, GIST-T1, established from gastrointestinal stromal tumor. Lab Invest 82: 663-665, 2002.

18. Hiroyuki S, Kazumasa F, Yoshiro S, et al: Establishment of imatinib-resistant GIST cell lines. PLoS One, 2014.

19. Isakov O, Perrone $M$ and Shomron N: Exome sequencing analysis: A guide to disease variant detection. Methods Mol Biol 1038: 137-158, 2013.

20. Sanger F and Coulson AR: The use of thin acrylamide gels for DNA sequencing. FEBS Lett 87: 107-110, 1978.

21. Pfaffl MW: A new mathematical model for relative quantification in realtime RT-PCR. Nucleic Acids Res 29: e45, 2001.

22. Smith PK, Krohn RI, Hermanson GT, Mallia AK, Gartner FH, Provenzano MD, Fujimoto EK, Goeke NM, Olson BJ and Klenk DC: Measurment of protein using bicinchoninic acid. Anal Biochem 150: 76-85, 1985.

23. Lasota $\mathbf{J}$ and Miettinen M: Clinical significance of oncogenic KIT and PDGFRA mutations in gastrointestinal stromal tumors. Histopathology 53: 245-266, 2008.

24. Coe TM, Fero KE, Fanta PT, Mallory RJ, Tang CM, Murphy JD and Sicklick JK: Population-based epidemiology and mortality of small malignant gastrointestinal stromal tumors in the USA. J Gastrointestinal Surg 6: 1132-1140, 2016.

25. Wilkening A, Rüb C, Sylvester M and Voos W: Analysis of heat-induced protein aggregation in human mitochondria. J Biol Chem 293: 11537-11552, 2018.

26. Pavlin D, Tozon N, Sersa G, Pogacnik A and Cemazar M: Efficient electrotransfection into canine muscle. Technol Cancer Res Treat 7: 45-54, 2008.

27. Jhas B, Sriskanthadevan S, Skrtic M, Sukhai MA, Voisin V, Jitkova Y, Gronda M, Hurren R, Laister RC, Bader GD, et al: Metabolic adaptation to chronic inhibition of mitochondrial protein synthesis in acute myeloid leukemia cells. PLoS One 8: e 58367, 2013 
28. Hershkovitz T, Kurolap A, Gonzaga-Jauregui C, Paperna T, Mory A, Wolf SE, Regeneron Genetics Center; Overton JD, Shuldiner AR, Saada A, et al: A novel TUFM homozygous variant in a child with mitochondrial cardiomyopathy expands the phenotype of combined oxidative phosphorylation deficiency 4. J Hum Genet 64: 589-595, 2019.

29. Sajid A, Arora G, Gupta M, Singhal A, Chakraborty K Nandicoori VK and Singh Y: Interaction of mycobacterium tuberculosis elongation factor Tu with GTP is regulated by phosphorylation. J Bacteriol 193: 5347-5358, 2011

30. Ravn K, Schönewolf-Greulich B, Hansen RM, Bohr AH Duno M, Wibrand F and Ostergaard E: Neonatal mitochondrial hepatoencephalopathy caused by novel GFM1 mutations. Mol Genet Metab Rep 3: 5-10, 2015.

31. Liu J, Fang H, Chi Z, Wu Z, Wei D, Mo D, Niu K, Balajee AS, Hei TK, Nie L and Zhao Y: XPD localizes in mitochondria and protects the mitochondrial genome from oxidative DNA damage. Nuclc Acids Res 43: 5476-5488, 2015.

32. Xi HQ, Zhang KC, Li JY, Cui JX, Zhao P and Chen L: Expression and clinicopathologic significance of TUFM and p53 for the normal-adenoma-carcinoma sequence in colorectal epithelia. World J Surg Oncol 15: 90, 2017.

33. Hashim YZHY, Worthington J, Allsopp P, Ternan NG, Brown EM, McCann MJ, Rowland IR, Esposto S, Servili M and Gill CIR: Virgin olive oil phenolics extract inhibit invasion of ht115 human colon cancer cells in vitro and in vivo. Food Funct 5: 1513-1519, 2014.

34. Zhang L, Xiao K, Zhao X, Sun X, Zhang J, Wang X, Zhu Y and Zhang X: Quantitative proteomics reveals key proteins regulated by eicosapentaenoic acid in endothelial activation. Biochem Biophys Res Commun 487: 464-469, 2017.

35. He K, Guo X, Liu Y, Li J, Hu Y, Wang D and Song J: TUFM induces epithelial-mesenchymal transition and invasion in lung cancer cells via a mechanism involving AMPK-GSK3 $\beta$ signaling. Cell Mol Life Sci 73: 2105-2121, 2016.
36. Geido E, Giaretti W and Nüsse M: Detection of M and early-G1 phase cells by scattering signals combined with identification of G1, S, and G2 phase cells. Methods Cell Biol 33: 149-156, 1990.

37. Lei Y,WenH, Yu Y,TaxmanDJ,ZhangL,WidmanDG,Swanson KV, Wen KW, Damania B, Moore CB, et al: The mitochondrial proteins NLRX1 and TUFM form a complex that regulates type 1 interferon and autophagy. Immunity 36: 933-946, 2012.

38. Rakovic A, Grünewald A, Voges L, Hofmann S, Orolicki S, Lohmann K and Klein C: PINK1-interacting proteins: Proteomic analysis of overexpressed PINK1. Parkinsons Dis 2011: 153979, 2011.

39. Lei Y, Kansy BA, Li J, Cong L, Liu Y, Trivedi S, Wen H, Ting JPY, Ouyang $\mathrm{H}$ and Ferris RL: EGFR-targeted $\mathrm{mAb}$ therapy modulates autophagy in head and neck squamous cell carcinoma through NLRX1-TUFM protein complex. Oncogene 35: 4698-4707, 2016.

40. Zottel A, Jovčevska I, Šamec N, Mlakar J, Šribar J, Križaj I, Vidmar MS and Komel R: Anti-vimentin, anti-TUFM, anti-NAP1L1 and anti-DPYSL2 nanobodies display cytotoxic effect and reduce glioblastoma cell migration. Ther Adv Med Oncol 12: 1758835920915302, 2020.

41. Samec N, Jovcevska I, Stojan J, Zottel A, Liovic M, Myers MP, Muyldermans S, Sribar J, Križaj I and Komel R: Glioblastoma-specific anti-TUFM nanobody for in-vitro immunoimaging and cancer stem cell targeting. Oncotarget 9: 17282,2018

This work is licensed under a Creative Commons Attribution-NonCommercial-NoDerivatives 4.0 International (CC BY-NC-ND 4.0) License. 